\title{
Whose domain and whose ontology? Preserving human radical reflexivity over the efficiency of automatically generated feedback alone
}

\author{
Amanda Russell Beattie, School of Languages and Social Sciences, Aston \\ University, A.R.BEATTIE@aston.ac.uk,
}

Sarah Hayes, College of Learning and Teaching (COLT), University of

Wolverhampton, Sarah.Hayes@wlv.ac.uk

\section{Introduction}

There are some forms of feedback in daily life that, though generated and delivered via a machine, we may welcome because they help us to function with ease. For example, in taking a wrong turn whilst driving, to be provided with explicit directional instructions from a Sat Nav, can save time and embarrassment from being late. This reduces the need to think too much about the route, inducing quite 'automatic' responses in a human driver, if progress is underway. However, a driver may not always agree with the pre-defined route that a Sat Nav provides, suddenly finding themselves stuck. At this point they may also experience emotional reactions as they seek to decide a way forward. A more reflexive response from the human behind the wheel is now needed. Human agency comes into play as they consider the choices open to them, in the light of their previous experience. As the driver, they have an option to turn the machine off, or to look at the road signs and opt for a route that is physically signposted. Perhaps frustrated by the Sat Nav-directed route, they might consult the scruffy old map they once used and still have in the car. Failing that, there is the possibility of winding down the window and asking a human being. Hopefully, the direction is made clearer through discussing it with the chosen person. It may not be though, because humans are fallible too.

Even in a short dialogue with someone we ask for directions we might learn something additional, interesting or reassuring, via the feedback they give us. They may impart local knowledge relating to the journey or place of destination, in reply to questions. Or they might express more personal empathy, about the frustrations of driving when new to an area. This kind of 'bodily feedback' (rather than algorithmic responses from machinery), sought from another human in order to complete a journey (yet one that was at first directed by a machine, signposts and even a map...) is often a brief encounter. Yet even brief forms of human feedback are different, to automatically generated feedback, such as that from a Sat Nav alone. After thanking a human adviser in the street, a driver may move swiftly on, either to complete their travel, or perhaps to resume the Sat Nav instructions. What emerges from this example, is a small illustration of feedback constituted across intertwined technical and human encounters in the form of networked learning.

The above learning scenario did not take place within a university, but it demonstrates how automatically generated feedback is contested and supplemented by physical encounters and human feedback. This enables interesting observations to be made on both 'fallibility' and 'reflexivity'. Soros argues:

The two principles are tied together like Siamese twins, but fallibility is the firstborn: without fallibility there would be no reflexivity. Both principles can be observed operating in the real world. (Soros, 2013: 310).

In the Sat Nav example, fallibility of a machine directing a driver led to emotional responses and a reflexive decision on the part of that driver to seek alternative forms of guidance. Feedback from other people in this driving situation may be short-lived, but in longer term learning relationships in universities more radical forms of mutually reflexive feedback between a student and teacher can develop. Such feedback encounters might be understood as 'networked', as they facilitate the authorial voices of students along a learning journey, across physical and virtual locations (in class, across email, in tutorials, across digital forums, in a café on campus, over a phone call or Skype). In a sense, fallibility opens the space for a reflexive response across all 
of these platforms. However, if the route of student learning is directed via algorithmic forms of technicallygenerated feedback alone, this may hamper what might now be considered 'postdigital' possibilities for learning. Recent theory suggests that students are now learning in a 'postdigital' era (Jandrić et al, 2018, Fawns, 2019, Hodgson and McConnell, 2019):

We are increasingly no longer in a world where digital technology and media is separate, virtual, 'other' to a 'natural' human and social life' (Jandrić et al., 2018)

With this in mind, we turn our attention towards examining these ideas in relation to universities and within the context of Networked Learning (NL) theory (Dirckinck-Holmfeld, Hodgson \& McConnell, 2011: 16). We question whether rapidly developing digital possibilities are being adapted to intervene in student learning with critical pedagogical insights, or to simply increase economic efficiencies for institutions. Furthermore, whilst 'technologies may arise in educational contexts, they are often developed and commercialised elsewhere and sold back to educational institutions as products', this means that education has become a consumer of technologies developed for other purposes (Jones, 2019). It is important to emphasise that (no matter how much efficiency is sought from a technical system in relation to learning), humans are still active participants (Soros, 2013: 311). Unfortunately, as contemporary Higher Education (HE) has become increasingly valued for its contribution to the global economy, students have become treated as consumers, who simply pay fees for educational 'products' (Hayes, 2015: 125; McRae, 2018). In an effort to provide good value for money, automated forms of feedback (such as those that might be developed in Turnitin or new artificial intelligence (AI) solutions) are being introduced alongside discrete modules for learning. The risk is that learning begins to resemble 'a set of tasks' (Hayes, 2015: 125) if new technological forms of automated feedback are all that students encounter. Then unfortunately, this may induce 'automatic' responses in students (not unlike the reactions described above when responding to a Sat Nav). Yet even in the face of such apparently objective feedback systems, human subjectivity has not been erased. Opportunities for more reflexive and mindful practices, in mutually constitutive feedback processes between teacher and student, have though been marginalised.

In this chapter, we challenge an increase in the uncritical application of similar algorithmic processes to those described above (in the form of a Sat Nav), for providing automatically generated feedback for students in HE. Though we define 'human feedback' as information arriving directly from a human being, and 'nonhuman feedback' as information arriving from algorithms and other 'thinking' machines created by human beings, we also see this as a rough classification. It is defined through its extremes. In reality (as shown by the Sat Nav example), forms of feedback for learning may fall anywhere within this continuum. Yet the human side of the feedback continuum seems to increasingly give way to the non-human side. A range of etechnologies and their algorithmic affordances are now called upon to meet the demands of time and space that emerge from within a neoliberal framing of contemporary Higher Education (HE) (Hayes \& Jandrić, 2017). Our initial concerns were in relation to observations on the e-marking platform Turnitin. However, generic pre-programmed student feedback delivered via Turnitin cannot be considered in isolation from other rapidly developing Artificial Intelligence (AI) systems now being applied in an HE context. For example, the introduction of facial recognition drone monitors to track students' facial expressions and emotions in class (Bhandari, 2018) adds another dimension to the huge amounts of data already being collected on the activities of students. Learning analytics and intelligent campus developments may arise from concerns for student wellbeing and progression, but they also open routes into economically driven manipulation of data and metrics and potentially dangerous forms of surveillance. If any of these systems are applied to extremes, at the non-human side of the feedback continuum, then we question where (under these circumstances) might we locate a student voice?

Initially, we place our concerns within the context of Networked Learning principles. These overlap with the notion that we are living in postdigital times. Therefore, in a sense, the 'postdigital' nature of our lives now reveals an increasing number of practical examples where networked learning theory is applicable. Networked Learning, NL hereafter, emerged in the later 1990s in reaction to technological determinism 'and as a way of critically examining that determinism' (Hodgson and McConnell, 2019). Articles concerned with the 'postdigital' are now pinpointing many instances of why it is necessary 'to push against, or move beyond, the simple 'solutionist' view of digital technologies' (Reeves, 2019) alone. Emerging postdigital perspectives, published in the journal of Postdigital Science and Education reject the notion that education can ever be entirely online or digital; instead, it always involves the combination of digital, biological, material and social (Jandrić et al, 2018, Fawns, 2019). As such, NL intersects across postdigital developments and radical pedagogies. 
Part one of this chapter interrogates the extreme end of the feedback continuum where non-human algorithmic affordances control feedback generation. We examine the e-marking platform Turnitin and some rapidly emerging developments of Artificial Intelligence (AI). Then Part two turns explicitly to the other end of the feedback continuum to discuss performing human 'radically reflexive feedback'. When generic (but power-laden) maps are now being incorporated into both student and staff 'perceived' spaces through AI, we surface the aspects of feedback that risk being lost. This part of the chapter draws on our own relational and lived experience as a demonstration of performing radically reflexive feedback within a Masters in Education programme. We discuss our own tutor/participant relationship which, from the outset, denied traditional forms of power and authority. Drawing on autoethnographic understandings (Ellis, Adams \& Bochner, 2011, Bartholomew, 2015) we discuss a mode of knowledge production that focuses on the experiences and interpretation of participants in their own learning narratives. We noticed that our own mutual offerings of feedback facilitated a form of radical reflexivity. We also became aware of the centrality of 'the body' when generating transformative feedback. Our emerging consciousness of the role that our human bodies and related vulnerabilities play in teaching and learning contexts, raises awareness of the lesser role that the body is often 'assigned' within neoliberal higher education, and now also via algorithmic culture and AI. Indeed, we point out the irony of technology to monitor facial expressions in class (Bhandari, 2018) when the topic of emotions is in reality an almost illicit conversation to be had within neoliberalism. In this vein we question on behalf of students and staff: where do we cry in higher education?

In the final section, we explore the insights generated from reflexively guided professional practice in the context of feedback. Radical reflexivity in the process of feedback supports students to seek out their own lived experience (Hayes, 2015: 132) and voice their own particular subjectivities within HE, when they may otherwise remain unaware of this voice. We suggest that a radically reflexive form of feedback is consistent with the development of NL and could empower students in new 'postdigital' learning encounters. Radically reflexive feedback can provoke a student voice and a route towards critical self-navigation. When automation threatens human employment, the characteristics of what it is to be creatively human need to be preserved (Peters, Jandrić \& Hayes, 2018, Peters, Jandrić and Means, 2019). As such we advocate for creative and mindful practices aligned with teaching and learning journeys, whatever new technological platforms are introduced. Learning should not be reduced to the 'sat-nav experience' alone, in terms of feedback. A more nuanced understanding of the range of human participation taking place in and around technological systems is necessary through NL and postdigital theories. We suggest that, as technology becomes ever more intimately embedded into our everyday lives, there is a risk we may not notice or contest how data and systems may be applied indiscriminately in HE to serve particular neoliberal agendas. Therefore, in automatic forms of feedback generated by AI, ethical issues are a primary concern:

We need to be clear what data is being processed, where, and how. And any actions or recommendations made by an AI need to be subject to human review (Hamilton, 2018).

It is important to question, as digital solutions are sought and applied within universities: where are the related critical pedagogies? Critical theories about emancipated forms of learning through feedback need to be considered in the policies we create for integration of AI into HE. Otherwise the individual student and staff voices and emotions simply become trapped in a generic 'iron cage' of 'the student experience' (Hayes and Jandrić, 2018). Under this universal policy banner, alternative values can become hushed, along with other ways of organising academic labour (Couldry, 2010: 12; Hayes, 2019). Like Amsler (2011) we challenge 'soft pedagogies' that encourage passive students and suggest instead that radically reflexive feedback has a particular role to play within her depiction of 'hard pedagogies'. We situate these arguments within the wider narrative of critical pedagogy and imagine instead a learning journey whereby teacher and students are co-producers of knowledge and share authorial privilege in the unfolding journey they embark upon together. A radically reflexive form of feedback may not follow a pre-defined route or map, but it does offer a vehicle to restore individual student and staff voices and critical self-navigation of both physical and virtual learning spaces. This needs to be preserved in the ongoing shaping of contemporary, postdigital HE.

\section{Networked Learning (NL) and Radically Reflexive Feedback}

Our initial arguments are closely linked to the underlying principles of NL: 
Which can be traced back to the critical pedagogy of Freire and emphasises a critical relationship with the digital, the human and the current socio-political and material higher educational context' (Hodgson and McConnell, 2019).

Educational feedback is a complex communicational, cultural, and social phenomenon. While it might be tempting to analyse feedback using the dichotomy between human and non-human communication, it is not enough to assume that there is a straightforward distinction between something 'human' and something 'technological' or 'algorithmic'. All these things have 'human' and political aspects too. However, this does not imply radical equality between feedback generated by a human being, and feedback created by an algorithm (which, under multiple layers of technology, is also created by human beings).

We therefore question what space remains for the human side of the feedback continuum, developed within a radically reflexive framework, if this gives way to algorithmic culture alone. Radically reflexive feedback is part of a wider transformative process that defies the notion of the 'student as consumer' or something generic referred to as 'the student experience' (Hayes and Jandrić, 2018). The role of feedback that we present challenges the logic of education as an economic transaction, calculated for us, via algorithms. It seeks, on the other hand, to enable each student to locate their own 'voice', and indeed their entire bodies as co-producers of knowledge and to contest increasingly negative iterations of their subjectivities within HE. We therefore emphasise the importance of connections between developments in technology and the "radical pedagogies and humanistic educational ideas from Dewey, Freire, Giroux and Rogers" that have characterised NL from the outset (Dirckinck-Holmfeld, Hodgson \& McConnell, 2011:4, Jandrić and Boras, 2015). If the emphasis is only on 'arriving' at, or 'producing' something, via technology, then what separates a university education from following the directions of a Sat Nav? Unfortunately, students receiving automatically generated feedback are not in a position to alter their direction of 'travel', unlike the driver of a car. The 'map' has been pre-programmed and there are no alternatives. Therefore, if technological forms of feedback are uncritically applied, a student route to learning in HE, through mindful contemplation and autonomous decisions, may swiftly become analogous to one simply driven by a sat nav, without alternatives.

NL developed initially as a critical pedagogical response in relation to new information and communication technologies and online learning programmes. Throughout its history, NL has been characterised by 'not separating pedagogical and socio-material aspects of integrating new technology into learning designs' (Hodgson and McConnell, 2019). Algorithms are now routinely designed in, and contribute to, an alteration of our sociotechnical learning spaces, therefore it is important that communities who have always approached technology critically now unite across disciplinary boundaries to strengthen their voice. Algorithms work within our 'lived space' in real time, as they calculate routes, data and procedures (Chesher, 2012: 315). As digital media increasingly mediate our everyday spatial and navigational practices (Chesher, 2012), there emerges a dominant e-structure that alters our educational spaces (Jandrić et al., 2017). There is therefore a pressing need now to contest the imagined role for algorithms in contemporary HE and confront this with research that has shaped the field of NL. A 'postdigital attitude' that 'inquires into the digital world, examining and critiquing its constitution, its theoretical orientation and its consequence' (Hodgson and McConnell, 2019) is well aligned with NLin cutting across both critical pedagogy and the socio-cultural designs of learning mediated by technology (Dirckinck-Holmfeld, Hodgson \& McConnell, 2011: 16). We turn now in Part One to discuss ways in which algorithmic cultures might suppress individual student voices. We consider both developments in AI and the algorithmic affordances of Turnitin software for marking and plagiarism detection. We seek to excavate the silences it creates in order to illustrate (in a learning context) the problems of a 'Sat Nav student experience'. The creative potential of a radically reflexive feedback relationship instead sustains a positive imagining of students as co-producers of knowledge.

\section{Part One: Al, Turnitin and the 'Sat Nav student experience'}

We begin with a particular understanding of algorithmic cultures (Jandrić et al., 2017). Drawing on the writings of Striphas (2015), we assume that algorithmic culture is "the enfolding of human thought, conduct, organisation and expression into the logic of big data and large-scale computation, a move that alters how the category of culture has long been practiced, experienced and understood" (Stiphas, 2015: 396). For Striphas, imposing order on information - via the use of algorithms to decide what can, and ought, to be disseminated - suggests a level of cultural elitism. While Striphas does not extend this argument to the realms of institutional learning design, it is not difficult to envision how such forms of elitism can inform both the professional practice of academics and the lived experience of students. For example, in adaptive learning the curriculum is modified to respond to the strengths and weaknesses of a person learning. Technology moves into the role of a coach or mentor and the goal is to improve student 
performance. However, our concern is what aspects of feedback may be silenced in such encounters with a machine. The provision of additional exercises by, for example, the DuoLingo language system (Hamilton, 2018) may improve basic language skills, but it is not even close to reflexive and mutually shared feedback between people. Chat bots are now offering out-of-hours help and advice to students. As Hamilton points out, these technologies work across time zones, will never take industrial action and won't need a pension (Hamilton, 2018). Yet basic advice is different to the role of a teaching assistant. For example, the BBC education correspondent Sean Coughlan wrote on 14 December 2016 of an AI teaching assistant used at Georgia Tech University. The article wonders if, and how, teaching will be transformed through the use of technology and automated workers in ways that mirrors other skills-based industries. Such developments have interesting implications for those delivering feedback. In his TedEx Talk, AI creator Ashok Goel discusses the motivation for creating the AI assistant named Jill Watson. He suggests this was to address the Frequently Asked Questions by students in order to help free up time for academics to attend to other tasks. Ashok is keen for teachers to embark on what he calls 'creative tasks' that would enable education to be accessible to all in a personal, and enjoyable, fashion. We wonder though where this leaves student creativity? While the BBC article notes how students chiefly enjoyed the timeliness of the replies, Coughlan describes how Jill Watson was programmed with a time delay to ensure that answers provided by AI did not arrive too soon after the original question was posed! Already we can see, within this unfolding negotiation, how the demands of time, and the unfolding expectations of students as consumers informs not only the demands for a particular type of feedback, but also how it subtly informs the affordances of AI as well.

Striphas (2015) provides a timely reminder of the etymology of algorithm noting that in its historical unfolding, and contemporary usage, algorithm is both about information inclusion and exclusion. He suggests that the use of algorithms to manage information is not unlike cryptology and code breaking. In deciding what information to include and exclude there is, at the heart, a human negotiation. It is within this negotiation that a desire to impose order on a vast amount of information emerges and a particular public image takes hold. Already, within the development of AI provisions of feedback a choice is being made to attend to timeliness, to the detriment of creativity. This has implications on the individual lived experiences of students and those of teachers too. Ashok attends to the voice of the programmer, and their relationship to the AI, in pioneering an AI teaching assistant. These voices are important because they make visible the stories behind algorithmic culture. Yet, at a time when 'the student experience' has become a widely adopted buzz phrase in policy discourse (Hayes and Jandrić, 2018, Hayes, 2019) we question: where, within this unfolding technology, are the voices of students?

Striphas (2015) recounts a particular challenge faced by Amazon.com when consumers noticed that gay literature was being excluded from top title rankings. When made aware of this particular form of silencing, individuals took to Twitter to voice their unhappiness. This trend was able to prompt a change of alorgithmic use on Amazon.com thereby allowing for the inclusion of gay literature in their public rankings. Striphas's example reveals how, when afforded a voice, individuals can use various forms of public negotiation as both a site of resistance and institutional change within politics. Indeed, his writings align with the work of Crawford (2016) who suggests a need to understand an agonistic quality within algorithmic cultures. She turns to the writings of Mouffe (2003) and distinguishes between 'the political' and 'politics', reminding readers of the agonistic quality within the political that informs a democratic practice. Crawford is invoking this agonistic ethos in order to query the focused interpretations of algorithmic technologies that might emerge if they are understood outside of their political environment. She suggests it is necessary to understand the affordances of algorithms if we are to better understand their wider political value and influence within society, and to a multiplicity of agents (Striphas, 2015)

We ask therefore, where, in the experience of AI and teaching, is the democratic voice of the student community? If we attend to the online platforms which inform e-marking and feedback, we can trace the beginnings of a virtual, but real, silencing of students. Their work is submitted online via an e-platform, for example, Turnitin, at which point the voice of the teacher dominates and any vestige of an agonistic framing of feedback is impossible to locate. Teachers that use Turnitin are though offered two spaces within which to provide student feedback. Firstly, there is a text box that allows up to 5000 characters whereby teachers can leave personal feedback aligned with the work they have critically reviewed. Feedback within this space is personal, tailored to the work submitted by the student, and can be in- depth and highly reflexive. Such an approach to student feedback, while valuable, does take time as it requires teachers to reflect and address particular areas of strength and weakness that can contribute to the development of the student cum researcher.

On the other hand, Turnitin also provides teachers with a series of pre-fabricated tabs that can be inserted by simply dragging and pasting the tab into the submitted text document. This approach to feedback is developed with an awareness of common mistakes made by undergraduate students and provides a 'one size fits all' approach to feedback, not unlike Jill Watson. What tabs to include on the Turnitin platform reflect a series of choices, but 
generated in an impersonal, and impartial manner, with implications for the transformative potential of students. We suggest that, rather than engage students in a transformative nature, conducive to reflexivity and growth, this software enhances the consumerist nature of contemporary HE. Introna (2016: 31) highlights the performative nature of Turnitin, as an 'algorithmic actor' embedded now in HE. Such technologies are suggested to be complicit alongside governing practices such as league tables, student satisfaction surveys, analytics and institutional audits, leading to traditional staff and student subjectivities and practices becoming reconstituted (Shore and Wright, 2004).

As student identities are now increasingly expected to take the form of customers and the academic as a related service provider, so "the academic essay (with its associated credits) is enacted as the site of economic exchange" (Introna, 2016: 33). Student submissions then become commodities to be verified through feedback that is simply a rating system that values the goods produced. From the point of view of students, we are aware from our own teaching, that they express anxiety and fear about committing plagiarism. Introna adds that 'they may even pay Turnitin to check them in order to certify themselves the owners of their texts, "just in case", (Introna, 2016: 39). These observations uphold points made by Zwagerman (2008) that the student teacher relationship now begins from a point of mistrust, as plagiarism detection takes priority over more mindful forms of exchange, where learning experiences might be co-produced. It is not until we move away from a calculative culture of systems and practices, where students are primarily occupied with not breaking the rules, that we can develop forms of self-interrogation to virtually eliminate tendencies to plagiarise. Perhaps most problematically is that this image of the student, both their ontology but also their embodied subjectivity, is unfolding without their knowledge, thus displaying a key difference to the algorithmic stories provided by Striphas. While his use of trending tweets reveals a capacity to engage and effect change, students in this lived experience remain unaware of their depiction within the institutional design of $\mathrm{HE}$ and the use of feedback and assessments to inform their lived experiences. If the task of teachers is to facilitate a transformative environment for their students, and thus afford them a voice of equal engagement in the learning journey, this image of students is problematic. It not only reinforces the passivity of the student, thus handicapping the ability to overcome a pedagogy of lack described by Kahane (2009), but also further reifies the soft pedagogy critically evaluated by Amsler (2011). Most problematically is that within this use of technology to augment a particular form of student, to the detriment of another, students lack a voice to challenge this imagining of their embodied portrayal as students.

We now return to Crawford (2016), as we use our own lived experience of feedback as a model of resistance to the missing student voices effected through AI and algorithmic culture. An algorithmic 'black box' discussed by Crawford (2016) needs to be exposed and so it is important to "unpack the warm human and institutional choices that lie behind these cold mechanisms" (Gillespie 2013:169). The risk if we do not, is that invisible "winners" and "losers" take part in hidden contests and accountability for these is lost (Crawford, 2016). It is only when we bring the human body back into the feedback process that we can establish the negotiations that give context to the algorithm being used to sustain HE. In order to excavate this postdigital challenge (Jandrić, et.al., 2018) we are informed by NL and critical pedagogy.

\section{Part Two: Where do we cry in higher education?}

Crawford (2016) acknowledges that we cannot begin to understand algorithmic calculations in isolation. We must, she suggests, understand the broader context in which they operate. Whilst algorithms are frequently discussed as 'powerful' they are influenced by complex values, ideologies, and practices of neoliberal pedagogy (Giroux, 2004). Neyland and Mollers argue for a move away from considering algorithms as having social power in the form of technological agents able to cause an effect on society. Instead, it is important to recognise the situated character of algorithmic systems in relation to individual narratives. Distinct components are designed and reworked as "they come together with rules, people, processes and specific kinds of relationships" (Neyland and Mollers, 2017: 59). Treated as a commodity, feedback is a part of a package we deliver to students who are already paying for their education. In the UK, it is represented through data to provide evidence for a Teaching Excellence Framework (TEF) (BIS, 2016), and discussed as an element that contributes to student 'learning gain'. This is one example of the public dimension of feedback, but this may overlook and diminish the private human spheres involved - and this is where we seek to respond. Feedback takes place in a set of circumstances, but always influenced by factors beyond the humans involved, and also linked to emotions. Whether the phone rings during the writing of student feedback, or a student reads or hears feedback in a physical class, or through a technological system, human and affective links are ever-present in that student's life. All factors have a bearing on how feedback messages are experienced by the contributing parties. Whilst Willis seeks to transcend a pedagogy prefaced on narratives alone, we wonder what value there is in a narrative of the human body, to inform a radically reflexive engagement with feedback in HE. Crawford (2014) writes: "If we broaden our scope to include the array of human and algorithmic 
actors developing a space, sometimes in collaboration, sometimes seeking to counter and outwit each other, we find a different narrative and a more diverse cast of political actors." (Crawford, 2014: 81) In seeking out this diversity, we suggest turning inwards, to what can seem to be almost illicit stories alongside more consumer-focused perspectives of HE. Yet, these are the narratives that inform our lived experience as academics. They re-invigorate an awareness of sensation, emotion, and practice as played out between relational bodies.

Intuitively we know that feedback is a human, even bodily, process. Yet this intuition only emerged from within a series of informal, and unplanned, discussions - conducted as a tutor and participant - on an MEd programme aimed at transformation (Hayes, 2015). We offer up, as a sign of our particular claims, our own lived, and relational, experiences of feedback on the MEd and as fellow teachers in HE. We suggest, in the spirit of Rowe (2012), that lived experience expressed as autoethnography brings theory and ideas to life. It enriches that natural encounter that must count for something in the ambition of an idea and a dedication to its cultivation and eventual realization. It is within Rowe's critique of neoliberalism and articulation of an erotic pedagogy that we find the courage to shock those that would recoil from an assumed illicit conversation. Within feedback there is a vulnerable power that can awaken a wider sense of self and creation within the production of knowledge. Feedback between us on the MEd (and as co-authors) was both formal and conversational. A compelling story emerges that suggests that feedback is both human and emotional and draws upon illicit forms of experience that are traditionally denied in neoliberal iterations of accepted knowledge production.

In our feedback sessions a relationship emerged that now informs a collegial friendship. This friendship embraces a form of vulnerability that encourages possibility. It probes the illicit and wonders at the creative potential when knowledge is informed by the personal and the emotional. There was, within our roles, a surrendering to a process that defied traditional HE roles. This process was constituted by a stepping back and forth between teacher and student, so that it became difficult to understand where one started and the other ended. It is hard to imagine how automatically generated feedback through an algorithm could respond in such a way. Instead our experience of feedback might have been replaced by the silencing discussed by Striphas (2015) in algorithmic cultures. The challenges of neoliberal expectations of professional practice tends to deny the emotionality of being human. So we sought to discover these silences, to excavate the human and respond to it, as we explored and reflected on practices of mindfulness within the MEd classroom. This revealed authenticity in personal accounts of practice and identity. These felt raw and emotional rather than sanitised or systemised to meet the expectations of neoliberal HE culture.

We engaged with and responded to practices of free writing. This helped us to acknowledge, with honesty, the roles of our bodies in writing. We learnt through our conversations that there is a physical presence to feedback sensations of heat and cool - love and sadness - knowing when you have gone far enough, or perhaps not far enough - the prickle of tears, the running of sweat, the racing of hearts. They are all actions and reactions and they are not captured if the feedback is enacted is only via technological experiences. Within these encounters there is a rush of exploration, of discovery, of the potential for ontology to push the boundaries of the illicit and open up the boundaries of vulnerability. Feedback, in the process of creation is not unlike the practice of yoga. The exhale is the relaxation. The inhale is the working process. In the sweat of exercising the body, astonishing revelations may enter the mind. Within the inhalation you ease into the process and you feel your way back into comfort. But in the spirit of transformation you know you can't stay there - that within the comfort there is a drive or desire to keep pushing to explore the boundaries and to negotiate anew what is emerging and becoming. Through mindfulness we can contemplate what spaces we open for 'lived' feedback - the breathing technique is a physical experience that provides a route to a more permanent change, where contemplative techniques remain with us. They do not fade as they might, if they are only thought, and not 'lived'.

Thinking through our experiences of this form of living feedback leads us to conclude that to breathe in this way challenges the instrumentality of neoliberalism. It renews our interest in connections between our bodily functions and our minds (Shahjahan, 2015; Hayes, 2015, Peters and Jandrić, 2018). The demand for constant activity and learned habits of electronic stimulation in modern society need not be negative, if these are tempered with contemplation. Hart (2004) suggests contemplative techniques provide a portal to our inner world. It is a world that as co-authors we have just begun to explore, where daily learning, living and feedback have intermingled. We dared to allow intimacy to develop in our feedback. This led to a wonder and excitement in what lies ahead. Our authentic and intimate lived experience of human feedback has reinvigorated how we in turn enact feedback with our own students, at least before robots take over to deliver feedback on our behalf (Coughlan, 2016).

Our conversations highlighted what Jaggar (1989) reveals in her telling work on emotions; that we can only start from where we begin. But beginnings are important, as they carry with them human experience that has gone before. Could any automated process really be programmed to be aware of multiple human life stories and the emotions 
therein? Furthermore, our emotional promptings when permitted to surface, can reveal a deeper sense of meaning in what we study. In essence, there is more than a simple desire to explain or understand. This drive to create, and produce new forms of knowledge, might just be more personal, and more human, than perhaps a neoliberal framing of knowledge creation might allow to be acknowledged. We embraced an overt need for emotions, as discussed in the reflexive notions espoused by Jaggar. With uncertainty, but faith in a wider sense of transformation within pedagogy, we repeatedly returned to the writings of hooks (2014) to find comfort in a role for both tears and joy in the classroom. Much like Rowe's critique of neoliberal eroticism, tears and emotions exist outside a defined iteration of the classroom leading us to wonder, where do we cry in higher education? Perhaps more broadly, where do we attend to the human in our iterations as both teachers and researchers in higher education? Emotions, like eroticism, are an illicit conversation to be had within neoliberalism. They render individuals insecure, revealing a vulnerability that, as Shildrick suggests, cannot be controlled for. While she documents within the history of ideas how various institutional approaches to vulnerability have sought to deny overt forms of vulnerability we suggest, instead in the spirit of Beattie and Schick (2013), that this treats vulnerability as an agonistic experience. Vulnerability is not a rational state, but when acknowledged within the feedback process, it does allow individuals and groups to negotiate their very ontology. From within this experience, new creative forms of understanding of the self, and the other, are revealed in feedback.

\section{Part Three: Towards radical reflexive feedback}

We contend that only humans can take this need for reflexive thinking and transformation further still, to re- apply what they have learned, and in so doing, to influence the learning of others. However, we also acknowledge the hybrid existence we all inhabit, whereby we are dialectically intertwined as both human and machine. Our learning experiences are always augmented to some degree by technology and we are politically implicated in its design (Winner, 1980). Transformation occurs in a relational context, with critical reflexivity and relational dialogue acknowledged as key concepts within networked learning (Dirckinck- Holmfeld, Hodgson \& McConnell, 2011: 291; Jandrić, 2017). We suggest that transformations require a form of radical reflexivity in feedback that acknowledges the relational component of being human across postdigital encounters. On the MEd this was enacted in the space between classroom encounters and the social media platform: Yammer. Yet, what emerged as dialogue across Yammer felt like an extension of the feedback shared in our physical classes. We would argue that this only became possible, through a shared radical reflexivity twined with mindfulness, that had helped us to contest power and authority in the HE classroom.

This situation must, by its very nature, defy traditional iterations of power and authority and imagine students, not as vessels, but rather as co-producers of knowledge and a key party to the iterative processes that algorithmic cultures remove. Ackerly and True (2008) suggest the need for academics to actively engage in a form of selfreflexive thinking in order to excavate the underlying relationships of power and authority that inform their relationships of research subject and researcher. Mauthner (2000) reflects on the ability, or inability of scholars, to engage on an emotional level within the production of knowledge. Autoethnographic disclosures can support these reflexive developments. Yet such disclosures also come at a cost. Many eschew autoethnographic reflections as mere navel gazing, a point not lost on Brigg and Bleiker (2010). Inayatullah (2011) reflects that it was only in sharing his own embodied experiences that he felt a deeper pull, or sense of connection, to those with whom he was relationally intertwined in his lived experiences. Autoethnographic reflexivity deepened his sense of the worlds in which he was a part. It is this sense of connectivity that was embraced in our development of a radical feedback experience. This experience emerges from abandoning traditional forms of pedagogy that reify technical rationality. We drew strength instead in the claims of Kahane (2008) whose experiences of free writing in the classroom generated a sense of honesty and authenticity. Not only were students to compelled to take on the role of community building in the classroom, they moved away from the hard pedagogy discussed by Amsler (2011). Kahane suggests a pedagogy of plenty whereby students and teachers co-produce the classroom experience and build relationships via the practices of mindfulness.

Intuitively it would seem that an individual experience emerges from within the intersection of pen and paper in free writing, perhaps foreclosing on the shared bodily experience of radical forms of feedback. We suggest otherwise. In opening up the quiet to reflect on personal, ontological lived experience and academic narratives, there is space to recall the emotionality of silence - space to wonder, experience, laugh and cry, and to recognise an active form of engagement within the writing journey. Reflecting inward does not lead to isolation. This form of vulnerability seems (in our experience) to prompt sharing, and within that, transformation. Individuals experience what Inayatullah (2011) describes as a form of necessary indulgence. Excavate the self and what do we find? Not essentialised indulgence, but dynamism (Inayatullah 2011: 8). Such dynamism is available to teachers and students 
alike. We suggest a radical form of feedback, accompanied by an autoethnographic interpretation of pedagogy can generate a community within the classroom that encourages engagement and not recipience. In itself it is both site and form of resistance to the iterations of the negative student image that informs contemporary HE. 


\section{Conclusion}

In conclusion, our arguments, situated within an autoethnographic account of teaching and learning, are for some, controversial. They are though linked to some key values of networked learning, such as: cooperation and collaboration in the learning process, self-determination, trust and investment of self in the networked learning process (Dirckinck-Holmfeld, Hodgson \& McConnell, 2011).

Therefore, we reiterate a challenge to the embodied portrayal of the HE student as AI systems take hold. The current depiction of students, within the technological, e-marking narrative and online platforms more generally suggests a sneaky character willing to take short cuts in the production of their work. This framing is unwittingly produced in a technological forum that shuts down conversations, leaving students largely in the dark and unaware of these assumptions. Yet in view of the introduction of a Teaching Excellence Framework (BIS, 2016) and emphasis on measuring the 'learning gain' of students, we suggest it is timely for the points we have raised to be a part of new institutional and management commitments to critically reflexive feedback processes. We hope, that in adopting a radically reflexive form of feedback we can contest this particular framing of students, as if they were of one universal identity (Hayes and Jandrić, 2018) thereby championing the notion of the student as a diverse co-producer of knowledge.

A radically reflexive interpretation of feedback welcomes students into a process where they reflect not only on their embodied experiences but also on the journey they wish to navigate as co-pilots within and beyond the classroom. It is not a simple 'sat nav' route. We suggest that as lecturers and students develop their feedback relationship there are opportunities for co-authorship, as we found as fellow academics through the MEd.

It provokes a series of conversations that provide a timely rejoinder to the calls of Amsler and Kahane, for a soft pedagogy of plenty that reifies the positive embodiments of the student and lecturer alike. We finish with an analogy of student journeys, in relation to the sat nav, 'which is not always a reliable guide to the road' (Chesher, 2012: 325). As Chesher points out:

Drivers on the road with sat navs also become 'users', as their information space is populated by databases and live information. Manufacturers promise this will give them greater command over the road: if there is traffic ahead, live traffic information will suggest changes to the route.....Find the cheapest petrol nearby, great food and shopping. Watch the estimated distance and time to destination, and live information. In each way that users open themselves to more information, they can open themselves to influences of advertising, tracking and other forces. Personal information spaces are overlaid by a growing array of information nodes, informing subjects about surrounding spaces. As these technosocial phenomena become more intimately embedded in everyday life, the hermeneutics of the technical, social and political forces, both 'trivial' and power-laden, must be taken seriously. (Chesher, 2012: 326-327).

We hope that our work provides, alongside such interventions, a vehicle for a student voice to challenge the negative assumptions surrounding their learning journey and their particular portrayal as consumers in the algorithmic framing of contemporary AI driven feedback experiences. A radically reflexive form of feedback is closely linked with the values of networked learning. It can provoke a student voice and a route towards critical self- navigation that is absent, but very much needed, in the ongoing shaping of contemporary HE.

\section{References}

Ackerly, B., \& True, J. (2008). Reflexivity in practice: Power and ethics in feminist research on international relations. International Studies Review, 10(4), 693-707.

Amsler, S. S. (2011). From 'therapeutic'to political education: The centrality of affective sensibility in critical pedagogy. Critical Studies in Education, 52(1), 47-63.

Beattie, A. R., \& Schick. K. (2013). The Vulnerable Subject: Beyond Rationalism in International Relations. London: Palgrave Macmillan.

Bhandari, B. (2018). Facial Recognition Drone Monitors Chinese College Class. Sixth Tone.

https://www.sixthtone.com/news/1002354/facial-recognition-drone-monitors-chinese-college-class

Brigg, M. and Bleiker, R. (2010). 'Autoethnographic International Relations: Exploring the Self as a Source of Knowledge', Review of International Studies, 36, 3, 779-798.

Business Innovation \& Skills (BIS) (2016) Teaching Excellence Framework Technical Consultation 
https://www.gov.uk/government/uploads/system/uploads/attachment_data/file/523340/bis-16-262-teachingexcellence-framework-techcon.pdf (Accessed 23 August 2017)

Carrillo Rowe, A. (2012) 'Erotic pedagogies'. Journal of Homosexuality 59, no. 7: 1031-1056

Chesher, C. (2012). Navigating sociotechnical spaces: Comparing computer games and sat navs as digital spatial media. Convergence, 18(3), 315-330.

Coughlan, S. (2014). Could Robots be Marking Your Work? http://www.bbc.co.uk/news/business-38289079 (Accessed 3 September 2017)

Couldry, N. (2010) Why Voice Matters: Culture and Politics After Neoliberalism. London: Sage Publications. Crawford K. and Gillespie, T. (2014). What is a Flag For? Social Media Reporting Tools and The Vocabulary of Complaint. New Media \& Society

Crawford, K. (2016). Can an Algorithm be Agonistic? Ten Scenes from Life in Calculated Publics. Science, Technology \& Human Values, 41(1), 77-92.

Dirckinck-Holmfeld, L., Hodgson, V., \& McConnell, D. (Eds.). (2011). Exploring the theory, pedagogy and practice of networked learning. Springer Science \& Business Media.

Ellis, C., Adams, T. E., \& Bochner, A. P. (2011). Autoethnography: an overview. Historical Social

Research/Historische Sozialforschung, 273-290.

Fawns, T. (2019). Postdigital Education in Design and Practice. Postdigital Science and Education.

Giroux, H. (2004). The terror of neoliberalism: Authoritarianism and the eclipse of Democracy. Boulder, CO:

Paradigm.

Goel, A. (2016). A teaching assistant named Jill Watson. TEDx Talk, You Tube:

https://www.youtube.com/watch?v=WbCguICyfTA (Accessed 28 August 2017)

Hamilton, M. (2018). Deep dreaming of AI in education. Jisc. https://www.jisc.ac.uk/reports/deep-dreaming-ofai-in-education

Hart, T. (2004). Opening the contemplative mind in the classroom. Journal of transformative education, 2(1), 2846.

Hayes, S. (2019). The Labour of Words in Higher Education: Is it Time to Reoccupy Policy?. Brill Sense.

Hayes, S. \& Jandrić, P. (2018). Resisting the Iron Cage of 'the Student Experience'. Šlsko polje, 29(1-2): 127143.

Hayes, S. \& Jandrić, P. (2017). Learning, technologies, and time in the age of global neoliberal capitalism.

Knowledge Cultures, 5(2), 11-17.

Hayes, S. (2015). 'Encouraging the intellectual craft of living research: tattoos, theory and time'. In Bartholomew, P, Guerin, C \& Nygaard, C. \& (Eds). Learning to Research -Researching to Learn. London: Libri Publishing Hodgson, V. \& McConnell, D. (2019). Networked Learning and Postdigital Education. Postdigital Science and Education

Inayatullah, N. (2011). Autobiographical International Relations: I, IR. London: Routledge

Introna, L.D. (2015). Algorithms, governance, and governmentality on governing academic writing. Science, Technology \& Human Values.

Jaggar, A. M. (1989). Love and knowledge: Emotion in feminist epistemology. Inquiry, 32(2), 151-176.

Jandrić, P., Knox, J., Besley, T., Ryberg, T., Suoranta, J., \& Hayes, S. (2018). Postdigital science and education. Educational Philosophy and Theory, 50(10), 893-899.

Jandrić, P. (2017). Learning in the Age of Digital Reason. Rotterdam: Sense.

Jandrić, P., Knox, J., Macleod, H., \& Sinclair, C. (2017). Learning in the age of algorithmic cultures.

E-Learning and Digital Media, 14(3), 101-104.

Jandrić, P. \& Boras, D. (Eds.). (2015). Critical Learning in Digital Networks. New York: Springer.

Jones, C. (2019). Capital, Neoliberalism and Educational Technology. Postdigital Science and Education

Kahane, D. (2009). Learning about obligation, compassion, and global justice: The place of contemplative pedagogy. New Directions for Teaching and Learning, 2009(118), 49-60.

Mauthner, M. (2000). Snippets and silences: Ethics and reflexivity in narratives of sistering. International Journal of Social Research Methodology, 3(4), 287-306.

McRae, A. (2018, February 22). What does 'value for money' mean for English

higher education? Times Higher Education. Retrieved October 10, 2018, from

https://www.timeshighereducation.com/features/what-does-value-money-mean- english-higher-education Mouffe, C. (2003). The Return of the Political. London: Verso.

Neyland, D., \& Möllers, N. (2017). Algorithmic IF... THEN rules and the conditions and consequences of power. Information, Communication \& Society, 20(1), 45-62.

Peters, M. A., Jandrić, P., \& Means, A. J. (Eds.). (2019). Education and technological unemployment.

Singapore: Springer. 
Peters, M. A., Jandrić, P., \& Hayes, S. (2018). The curious promise of educationalising technological unemployment: What can places of learning really do about the future of work? Educational Philosophy and Theory, 1-13. doi:10.1080/00131857.201 8.1439376

Peters, M. A. \& Jandrić, P. (2018). The Digital University: A Dialogue and Manifesto. New York: Peter Lang.

Reeves, T. (2019). A Postdigital Perspective on Organisations. Postdigital Science and Education.

Shahjahan, R. A. (2015). Being 'lazy' and slowing down: Toward decolonising time, our body, and pedagogy. Educational Philosophy and Theory, 47(5), 488-501

Shore, C, and Wright, S. (2004). "Whose Accountability? Governmentality and the Auditing of Universities." Parallax 10 (2): 100-16.

Soros, G. (2013) Fallibility, reflexivity, and the human uncertainty principle, Journal of Economic Methodology, 20:4, 309-329

Striphas, T. (2015). Algorithmic culture. European Journal of Cultural Studies, 18(4-5), 395-412.

Winner, L. (1980). Do artifacts have politics? Daedalus, 121-136.

Zwagerman, S. (2008). The scarlet P: Plagiarism, panopticism, and the rhetoric of academic integrity. College Composition and Communication, 676-71 




